\title{
Heterogeneous light delayed leaf senescence and ensure yield in maize
}

\author{
lingyang feng ${ }^{1}$, Muhanmmad Ali Raza ${ }^{1}$, Shu Yuan ${ }^{1}$, Zaheer Ahmed ${ }^{2}$, Jianyi Shi ${ }^{1}$, Yushan \\ $\mathrm{Wu}^{1}$, Ling Zhang ${ }^{3}$, Taiwen Yong ${ }^{1}$, Yanhong Yan ${ }^{1}$, Feng Yang ${ }^{1}$, and Wen-yu Yang ${ }^{1}$ \\ ${ }^{1}$ Sichuan Agricultural University - Chengdu Campus \\ ${ }^{2}$ University of Agriculture Faisalabad \\ ${ }^{3}$ Jilin Academy of Agricultural Sciences
}

January 17, 2022

\begin{abstract}
As an essential regulator of photosynthesis and hormone signaling, light plays a critical role in leaf senescence and yield gain in crops. Previously, numerous studies have shown that the narrow-wide-row planting pattern, especially under intercropping systems, is more beneficial for crops to enhance light interception, energy conversion, and yield improvement. However, the narrow-wide-row planting pattern inevitably leads to a heterogeneous light environment for crops (i. e., maize in maize-based intercropping systems) on both sides of the plant. The mechanism by which it affects leaf senescence and yield of maize under a narrow-wide-row planting pattern is still unclear. Therefore, in this study, we compared the leaf senescence and yield formation process of maize under homogeneous (normal light, NL and full shade, FS) and heterogeneous (partial light, PL) light conditions. Results revealed that partial light treatment influenced the homeostasis of growth and senescence hormones by regulating the expression of ZmPHYA and ZmPIF5. Compared to normal light and full shade treatments, partial light delayed leaf senescence by 3.6 and 5.9 days with 2.2 and 3.3 more green leaves and 1.1 and 1.4 fold nitrogen uptake, respectively. Partial light reduced oxidative stress by enhancing antioxidant enzyme activities of PS (shade side of partial light) leaves, which improved photosynthetic assimilation, balanced sucrose, and starch ultimately maintaining the similar maize yield to NL. Overall, these results are important for understanding the mechanism of leaf senescence in maize, especially under heterogeneous light environments, which maize experienced in maize-based intercropping systems. Furthermore, these findings are providing proof of getting a high yield of maize with less land in intercropping systems. Thus, we can conclude that maize-based intercropping systems can be used for obtaining high maize yields maintained under the current climate change scenario.
\end{abstract}

\section{Heterogeneous light delayed leaf senescence and ensure yield in maize}

Lingyang Feng ${ }^{\mathrm{a}, \mathrm{b}+}$, Muhanmmad Ali Raza ${ }^{\mathrm{a}+}$, Shu Yuan ${ }^{\mathrm{c}+}$, Zaheer Ahmed ${ }^{\mathrm{d}+}$, Jianyi Shi ${ }^{\mathrm{a}}$, Yushan $\mathrm{Wu}^{\mathrm{a}}$, Ling Zhang ${ }^{\mathrm{e}}$, Taiwen Yong ${ }^{\mathrm{a}}$, Yanhong Yan $^{\mathrm{f}}$, Feng Yang ${ }^{\mathrm{a}^{*}}$, Wenyu Yang ${ }^{\mathrm{a}^{*}}$

${ }^{a}$ College of Agronomy, Sichuan Engineering Research Center for Crop Strip Intercropping System, Key Laboratory of Crop Ecophysiology and Farming System in Southwest China, Sichuan Agricultural University, Chengdu 611130, PR China.

b Institute of Advanced Agricultural Sciences, Peking University, Weifang 261200, PR China.

${ }^{c}$ College of Resources, Sichuan Agricultural University, Chengdu 611130, PR China.

${ }^{\mathrm{d}}$ Department of Plant Breeding and Genetics, Center for Advanced Studies in Agriculture and Food Security (USPCAS-AFS), University of Agriculture Faisalabad, 38000 Pakistan. 
${ }^{\mathrm{e}}$ Institute of Agricultural Biotechnology, Jilin Academy of Agricultural Sciences, Changchun 130124, PR China.

${ }^{\mathrm{f}}$ College of Animal Science and Technology, Sichuan Agricultural University, Chengdu 611130, PR China.

${ }^{*}$ Corresponding authors.

*Yang Feng ;f.yang@sicau.edu.cn; ${ }^{*}$ Yang Wenyu;mssiyangwy@sicau.edu.cn

Tel.: +28 86290960; fax: +2886290870 .

${ }^{+}$These authors contributed equally to this work.

\begin{abstract}
As an essential regulator of photosynthesis and hormone signaling, light plays a critical role in leaf senescence and yield gain in crops. Previously, numerous studies have shown that the narrow-wide-row planting pattern, especially under intercropping systems, is more beneficial for crops to enhance light interception, energy conversion, and yield improvement. However, the narrow-wide-row planting pattern inevitably leads to a heterogeneous light environment for crops (i. e., maize in maize-based intercropping systems) on both sides of the plant. The mechanism by which it affects leaf senescence and yield of maize under a narrow-widerow planting pattern is still unclear. Therefore, in this study, we compared the leaf senescence and yield formation process of maize under homogeneous (normal light, NL and full shade, FS) and heterogeneous (partial light, PL) light conditions. Results revealed that partial light treatment influenced the homeostasis of growth and senescence hormones by regulating the expression of ZmPHYA and ZmPIF5. Compared to normal light and full shade treatments, partial light delayed leaf senescence by 3.6 and 5.9 days with 2.2 and 3.3 more green leaves and 1.1 and 1.4 fold nitrogen uptake, respectively. Partial light reduced oxidative stress by enhancing antioxidant enzyme activities of PS (shade side of partial light) leaves, which improved photosynthetic assimilation, balanced sucrose, and starch ultimately maintaining the similar maize yield to NL. Overall, these results are important for understanding the mechanism of leaf senescence in maize, especially under heterogeneous light environments, which maize experienced in maize-based intercropping systems. Furthermore, these findings are providing proof of getting a high yield of maize with less land in intercropping systems. Thus, we can conclude that maize-based intercropping systems can be used for obtaining high maize yields maintained under the current climate change scenario.
\end{abstract}

Key-words : maize; heterogeneous light; leaf senescence; phytohormone; phytochrome

\title{
Introduction
}

Leaf senescence (LS) is an age-dependent, genetically regulated process (Sakuraba et al., 2014) and is considered the last stage of leaf development (Brouwer et al., 2012). Therefore, as a declining phase of leaf development, it induces several catabolic activities in leaves. For instance, LS includes the degradation of protein, nucleic acids, and chlorophyll, destabilization of intercellular organelles, and limiting the remobilization of nutrients to developing tissues and storage organs (Buchanan-Wollaston et al., 2003; Leopold, 1961; Masclaux-Daubresse et al., 2008; Smart, 1994). Besides aging, various environmental stresses, like low light conditions, drought, salinity, and high or low temperature, can also initiate the process of LS during plant growth and development (Lim et al., 2007). Interestingly, moderate stress stimulation, depending on the interaction of environmental factors and phytohormone signals, could create an adaptive balance between plant growth and defense (Brouwer et al., 2012; Matyssek et al., 2002). In the above studies, all plants grow in a homogeneous environment. However, the molecular communication to regulate the carbon metabolism and signaling of plant hormones between the two sides of a plant to regulate leaf senescence and overall yield under a heterogenous light environment still invites a deep investigation at the physio-molecular level.

Earlier, genetic investigations in Arabidopsis thaliana have discovered numerous senescence-associated genes (SAGs) and the genes associated with plant hormone signaling (Lim et al., 2007). Generally, auxin plays an important role in suppressing leaf senescence (Lim et al., 2003). Decreased auxin levels may signal or enhance the onset of senescence, and levels of IAA reduce as a result of LS in various plants (Jiang et al., 
2014; Kim et al., 2011; Shoji et al., 1951; Uzelac et al., 2016). Several Auxin Response Factors (ARF) affect different aspects of senescence depending upon the target promoters (Tiwari et al., 2003). Previously, ARF2, ARF7, and ARF19 have been reported as repressors for auxin signals and suppress the expression of senescence-associated genes (SAGs) (Ellis et al., 2005; Lim et al., 2010; Lin \& Wu, 2004). Another important phytohormone, gibberellin, promotes senescence on the transition from vegetative to reproductive growth. Therefore, plants exhibited precocious developmental senescence upon applying bioactive GA3 and the absence of GA pathway repressor DELLAs (Schippers et al., 2015). Notably, the mode of action and the influence of different phytohormones over the regulation of senescence mechanism vary among different plant hormones. Like, ethylene signaling or biosynthesis genes directly regulate the time of senescence while the increased abscisic acid level in leaves promotes chloroplast degradation and repress chloroplast biosynthesis genes (Bennett et al., 2014; Liang et al., 2014). Furthermore, the treatment of plants with jasmonic or salicylic acid accelerated the senescence (Ueda et al., 1981; Morris et al., 2000), in contrast, application of cytokinins delayed the senescence (Gan and Amasino, 1995). Similarly, the knockout of ethylene receptor1-1 andabscisic acid receptor 9 enhance stress resistance and delay leaf senescence (Grbic \& Bleecker, 2010; Zhao et al., 2016). Taken together, it establishes the fact that the study of the individual role and mutual interaction of various plant hormones are very important to investigate the signaling and development of plant growth stages under prevailing environmental conditions. However, the mechanism involving the change in phytohormone levels and their interaction to regulate leaf senescence under a heterogeneous light environment, particularly under the circumstances of intercropping systems, is still unclear.

Different light environments could impact photosynthetic carbon fixation and its regulation by directing the leaf senescence, which could influence plant growth and development at a later stage (Grbic \& Bleecker, 2010; Velerskov, 2006). For instance, in a wide-narrow planting pattern, the crop is exposed to different light conditions, i.e., wide row (light side) and narrow row (shade side). In this perspective, some latest studies showed that narrow-wide row planting patterns changed the light environment and affected the carbon balance and senescence (Chen et al., 2020; Feng et al., 2020). Interestingly, half shading improved the photosynthesis and light utilization efficiency of maize leaves (Huang et al., 2019; Sun et al., 2019). Earlier, it was also shown that low light conditions induce or delay the leaf senescence process depending on the photosynthetic health of the plants (Keech et al., 2007; Keech et al., 2010). Similarly, the LS process of older leaves was reduced when plants were allowed to grow under darkness or shaded conditions (Tadahiko et al., 1993; Trejo-Arellano et al., 2020). Moreover, the delay in LS was reported to influence the productivity of intercropped species by prolonged grain filling time, increased resource use efficiency, and high land equivalent ratio (Chen et al., 2020; Feng et al., 2020). Therefore, the light-influenced senescence of leaves could affect the seed yield and seed quality of crops (Buchanan-Wollaston et al., 2003; Lam, 2004). Altogether, these reports suggest a deep understanding of the LS process under different growth conditions as an essential prerequisite for optimizing the light use efficiency and yield of multiple-cropping systems.

The maize soybean intercropping system hosts a diverse light environment in quantity and quality. Consequently, varying abundance of red light and far-red light (FR) could influence the response of different light receptors and phytohormones which could induce different senescence processes of leaves in intercropped maize. For instance, under partial shade, FR light receptor phytochrome A (PHYA), which maintains the leaf chlorophyll content, does not induce leaf senescence directly, while red light receptor phytochrome B (PHYB) mediates leaf senescence in the whole shading process (Brouwer et al., 2014; Lim et al., 2018). It has been reported that the Pfr form of phyB inhibits LS by repressing PIF4/PIF5 at the transcriptional and post-translational levels, respectively. Notably, in the dark, these PIF4/PIF5 directly activate the two bZIPs (ABI5 and EEL) and EIN3 (Sakuraba et al., 2014). Interestingly, shade-induced senescence of leaves can be prevented by limiting the shade duration with red light. Upon transferring to normal light conditions, FR light can also initiate LS (Pons \& de Jong, 2004; Rousseaux et al., 1997). Due to this, the low-light-induced LS at higher planting densities has been ascribed to the relative increase in FR light (Barreiro et al., 1992; Rousseaux et al., 1996). On the other hand, numerous scientists have reported that initiation of the LS depends on light quantity compared to light quality (Brouwer et al., 2012; Sakuraba et al., 2014). Similarly, several reports have proposed that when the quantity of light decreases below the photosynthetic-light- 
compensation-point (LCP), it decreases the carbon production in plants by reducing the photosynthetic rate enhanced LS (Boonman et al., 2006). Such reports indicate that improved light conditions in agricultural fields can reduce the LS of crops at higher planting densities or under intercropping systems. Therefore, to ascertain the role of light in intercropping, a deep investigation about the response of maize plants under differing light environments is required.

Notably, the maize soybean intercropping systems can guarantee maize yields with less land comparable to sole cropping and obtain an additional soybean yield. How is it possible? This research aimed to explore why maize leaf senescence was delayed and how the heterogenous light-induced phytohormone changes and carbon communication under this system. Given the dichotomous light conditions around maize plants in intercropping systems, we hypothesized that the two side leaves could express different regulatory mechanisms that could influence the overall growth and metabolism in maize plants. Therefore, we adopted a simulated approach to verify our hypothesis and designed an in-depth investigation about the metabolic and leaf senescence regulations at the morphological, physiological, and molecular levels.

\section{Materials and Methods}

\section{Plant Materials and Growth Conditions}

Maize (Zea mays ) cultivar Zhongyu 3 widely planted in maize soybean relay strip intercropping in China was used in this study. Maize seeds were pre-germinated on a sterilized, wet gauze for three days at 25 in a light chamber (I-66VL, Percival Scientific Inc., Watson, USA). Each germinated seed was transferred in a pot with $20 \mathrm{~cm}$ height and $30 \mathrm{~cm}$ diameter, filled with a mixed matrix of PINDSTRUP organic soil (Pindstrup Mosebrug A/S, Ryomgaard, Denmark). After three weeks, the plants were subjected to simulated heterogeneous light conditions (Normal light; NL and Partial light; PL) till the flowering stage (i.e. 76 days after sowing (DAS) (Fig.1A). The normal light (NL) intensity which was measured on a clear and cloudless weather day was about $1200 \mu \mathrm{mol} \mathrm{m} \mathrm{m}^{-2} \mathrm{~s}^{-1}$ and $80 \%$ transmittance of NL in the simulated shade was considered as partial light (PL). One side of maize was fully exposed to existing light conditions (Normal full-NF in NL and Partial full-PF in PL), and the other side was shaded using a black sunshade (Normal shade-NS and Partial shade-PS in NL and PL, respectively). Both sides of maize shaded by a black sunshade ( $80 \%$ transmittance of normal light) were used as a negative control (Full shade-FS; Supporting Information Figure $\mathrm{S} 1)$ for phenotypic analyses. The maize ear leaves were harvested on the $0,1^{\text {st }}, 10^{\text {th }}, 20^{\text {th }}, 30^{\text {th }}$, and $40^{\text {th }}$ days after light treatment for analyses. At maturity, dry seed matter accumulation with an interval of 5 days was determined on maize plants under normal light and partial shading. The place was exchanged between the pots daily to avoid any possible boundary effects. HR350 (Hi-point Inc., Gaoxiong, Taiwan) was used for light intensity and spectral irradiance $(\lambda=380-760 \mathrm{~nm})$ measurement. To further confirm the experimental results. Every treatment was performed with three replicates.

\section{${ }^{13} \mathrm{C}$ labeling and abundance analysis}

The maize ear leaf was labeled with ${ }^{13} \mathrm{C}-\mathrm{CO}_{2}$ at the flowering stage, as Supporting Information Figure S2. The ear leaf was covered in $\mathrm{a}^{13} \mathrm{C}-\mathrm{CO}_{2}$ labeling bag (material: biaxially oriented polypropylene film (BOPPF); standard: width $\times$ length $\times$ thickness $=12 \times 120 \times 2 \mathrm{~cm}$ ) and injected with $100 \mathrm{~mL}{ }^{13} \mathrm{C}_{-} \mathrm{CO}_{2}$. Mixed $\mathrm{CO}_{2}$ from the leaf tip to the bottom was carefully anchored with a nylon rope to avoid breaking by external factors, e.g., wind. Both sides of maize plants were marked differently to avoid any possible confusion. The tissue samples for analyses were taken after $1,10,20,30,40$ days ${ }^{13} \mathrm{C}$ labeling. The activity of ${ }^{13} \mathrm{C}$ was determined by the previously described (Liu et al., 2015) procedure. The abundance of ${ }^{13} \mathrm{C}$ was established using an isotope ratio mass spectrometer (Delta VIRMS Thermo Fisher Scientific, USA).

\section{Measurement of Chlorophyll (Chl) pigments and greenness}

A puncher obtained uniform size leaf discs $(1.2 \mathrm{~cm}$ diameters $)$ to measure chlorophyll concentration. Chl pigments were extracted with $80 \%$ ice-cold acetone, and the absorbance of $\mathrm{Chl}$ a and $\mathrm{Chl} \mathrm{b}$ was measured using an ultraviolet/visible spectrophotometer ( DU-730, Beck Man Coulter Inc., USA) according to the previous method (Feng et al., 2019). Maize leaf greenness was measured by spad-502 plus (Konika-Minolta 
company, Tokyo, Japan).

\section{Photosynthetic gas exchange characteristics}

Photosynthetic parameters, including net photosynthetic rate $\left(P_{\mathrm{n}}\right)$, transpiration rate $\left(T_{\mathrm{r}}\right)$, stomatal conductance $\left(G_{\mathrm{s}}\right)$, and intercellular $\mathrm{CO}_{2}$ concentration (Mutlu et al.), were analyzed by using a portable photosynthesis system (Li-6400; LI-COR Inc., Lincoln, NE, USA) at six different positions from each leaf and presented as average. All the parameters were measured before noon (between 9:00 AM to 11:00 AM) under a steady light intensity of $1000 \mu \mathrm{mol} \mathrm{m}{ }^{-2} \mathrm{~s}^{-1}$, environment temperature $25^{\circ} \mathrm{C}$, and a $\mathrm{CO}_{2}$ concentration of $400\left(\mu \mathrm{mol} \mathrm{mol}{ }^{-1}\right)$.

\section{ROS staining}

Histochemical staining for the qualitative detection of superoxide and peroxide radicals was performed with nitro blue tetrazolium (NBT, Sangon Biotech Co., Ltd, Shanghai, China) and 3,3-diaminobenzidine (DAB, Sigma-aidrich Inc., Darmstadt, Germany), respectively, as described previously (Zhang et al., 2013). Seedlings were excised at the base with a razor blade and supplied through the cut ends with NBT $(0.5 \mathrm{mg}$ $\left.\mathrm{mL}^{-1}\right)$ or DAB $\left(2 \mathrm{mg} \mathrm{mL}^{-1}\right)$ solutions for eight hours. Leaves were then decolorized in boiling ethanol (95 $\%$ ) for 20 min. At least three leaves were used for each treatment.

\section{Antioxidant enzyme activity assay}

Enzymes activity was measured by grinding $0.5 \mathrm{~g}$ of maize leaves in $2 \mathrm{~mL}$ ice-cold $25 \mathrm{mM}$ HERPES buffer (pH7.8) containing $0.2 \mathrm{mM}$ EDTA, $2 \mathrm{Mm}$ ascorbate, and 2\% PVP. The homogenates were centrifuged at 4 for $15 \mathrm{~min}$ at 13,000 $\mathrm{g}$, and the supernatant was used for enzyme activities assay. All steps in the preparation of the enzyme extract were carried out at 4. POD and SOD activities were measured as previously described (Zhang et al., 2016). $1 \mathrm{U}$ of CAT activity was considered a decrease in absorbance of 0.01 at $\mathrm{OD}_{240} \mathrm{~nm}$ minute $^{-1}$ (Wang et al., 2017b).

\section{$\mathrm{H}_{2} \mathrm{O}_{2}$, superoxide, and MDA quantification}

$\mathrm{H}_{2} \mathrm{O}_{2}$ activity was evaluated according to previous studies (Bawa et al., 2019). Plant tissues (0.4 g) were homogenized in $1 \mathrm{~mL}$ of $0.1 \%(\mathrm{w} / \mathrm{v})$ trichloroacetic acid (TCA) on ice. The homogenate was centrifuged at $12000 \mathrm{~g}$ for $15 \mathrm{~min} .1 \mathrm{~cm}^{3}$ of potassium phosphate buffer, and $1 \mathrm{~cm}^{3}$ of potassium iodide (KI) were added to $0.5 \mathrm{~cm}^{3}$ aliquot of the supernatant. The absorbance of the supernatant was measured at $390 \mathrm{~nm}$, and $\mathrm{H}_{2} \mathrm{O}_{2}$ content was calculated using a standard curve. Superoxide was determined by the hydroxylamine method (Elstner \& Heupel, 1976). The MDA content was measured with thiobarbituric acid reactive substances (Cao et al., 2009). $0.5 \mathrm{~g}$ leaves sample was homogenized in $5 \mathrm{~cm}^{3}$ of $0.1 \%(\mathrm{w} / \mathrm{v}$ ) trichloroacetic acid (TCA) and centrifuged at $10000 \times \mathrm{g}$ for $20 \mathrm{~min}$. To $1 \mathrm{~cm}^{3}$ aliquot of the supernatant, $4 \mathrm{~cm}^{3}$ of $0.5 \%$ thiobarbituric acid (TBA), dissolved in 20\% TCA, was added. The resulting mixture was heated at $95{ }^{\circ} \mathrm{C}$ for 30 min and then quickly cooled in an ice bath. Then, the supernatant was centrifugated at 10,000 g for $15 \mathrm{~min}$, and the absorbance was measured at 532 and $600 \mathrm{~nm}$. The value of non-specific absorption at $600 \mathrm{~nm}$ was subtracted from that of $532 \mathrm{~nm}$. The concentration of MDA was calculated using an absorption coefficient of $155 \mathrm{~nm}$.

\section{Nitrogen uptake, carbohydrates quantification}

An automatic Kjeldahl instrument determined total leaf nitrogen content (Kjeldahl 8400, FOSS, Denmark). To determine various sugars, maize leaves were harvested and dried to a constant weight at $80{ }^{\circ} \mathrm{C}$ in an oven. Sucrose and starch contents were measured as previously described (Feng et al., 2019).

\section{Starch degradation and sucrose biosynthesis enzymes analysis}

Fresh maize leaves $(1.5 \mathrm{~g})$ were ground in an ice-cold mortar containing $4 \mathrm{~mL}$ pre-cold $0.1 \mathrm{M}$ citric acid buffer (pH 5.6). The extract was centrifuged at $4{ }^{\circ} \mathrm{C}, 10000 \mathrm{~g}$, for $5 \mathrm{~min} .1 \mathrm{~mL}$ was transferred to two tubes separately and diluted 10 times from the supernatant. One tube was used for the measurement of total amylase activity and the other tube was kept at $70{ }^{\circ} \mathrm{C}$ for $15 \mathrm{~min}$ for $\alpha$-amylase activity determination. A maltose standard curve was used to calculate the total amylase and $\alpha$-amylase activities. The $\beta$-amylase 
activity was obtained by subtracting the $\alpha$-amylase activity from the total amylase activity. $1 \mathrm{U}$ enzyme activity was defined as $1 \mathrm{mg}$ protein degradation starch into $1 \mathrm{mg}$ maltose in $1 \mathrm{~min}$ at 37 and $\mathrm{pH}$ 5.6. Starch phosphorylase (SP) was extracted by adding $4 \mathrm{~mL}$ extraction buffer (contains $0.1 \mathrm{M}$ sodium succinate; $10 \%$ glycerol, $15 \mathrm{mM}$ mercaptoethanol, $1 \mathrm{mM}$ EDTA, $5 \mathrm{mM} \mathrm{MgCl}_{2}, \mathrm{pH} 5.8$ ) to $1.5 \mathrm{~g}$ leaf sample. The homogenate was centrifuged at $4{ }^{\circ} \mathrm{C}$, at $16000 \mathrm{~g}$ for $10 \mathrm{~min}$. The SP activity was calculated by an inorganic phosphorus (Pi) standard curve. The buffer (0.1 M MES-NaOH, pH 6.5; $5 \mathrm{mM} \mathrm{MgCl} 2 ; 2 \mathrm{mM}$ EDTA; $50 \mathrm{mM}$ mercaptoethanol; $12.5 \%(\mathrm{~V} / \mathrm{V})$ glycerol) was used for the extraction of starch debranching enzymes (DBEs). The homogenate was centrifuged at $4{ }^{\circ} \mathrm{C}, 16000 \mathrm{rpm}$ for $10 \mathrm{~min}$. Then $100 \mu \mathrm{L}$ DBE supernatant and equal volume $50 \mathrm{mM}$ MES-NaOH (pH 6.5) was added in a $2-\mathrm{mL}$ tube and kept at $37 \mathrm{for} 1.5 \mathrm{~h}$. Then $100 \mu \mathrm{L}$ of $1 \mathrm{M} \mathrm{Na}_{2} \mathrm{CO}_{3}$ was added to end the reaction, MiniQ water was added in the tube to make the final volume $500 \mu \mathrm{L}$. The DBE activity was measured using a 3,5-dinitro salicylic acid method at $525 \mathrm{~nm}$. The activities of sucrose synthase (SS) and sucrose phosphate synthase (SPS) were determined as the method by Feng et al. (2019).

\section{Phytohormones analysis}

Fresh maize leaves were cut and transferred into liquid nitrogen immediately. The samples $0.4 \mathrm{~g}$ were completely ground and $1 \mathrm{~mL}$ of a mixture solution (methanol: formic acid: water=15:1:4, v/v/v) was added for extraction. Purification was done using the dual-mode solid-phase extraction method (Dobrev \& Kamínek, 2002). Analysis of endogenous phytohormones, abscisic acid (ABA), Auxin (IAA), and gibberellin (GA) was done according to a previously described method (Meng et al., 2016). In addition, ethylene measurement is described earlier (Murad et al., 2021; Zaidi et al., 2016).

\section{Reverse transcription and qRT-PCR}

Total RNA from plant tissues was isolated using the Total RNA Extraction Kit (iNtRON Biotechnology, Korea). For reverse transcription (RT), first-strand cDNAs were prepared with $5 \mu \mathrm{g}$ of total RNA using M-MLV reverse transcriptase and oligo 15 primer (Promega) and diluted to $50 \mu \mathrm{L}$ with miniQ water. Gene expression levels were measured by qPCR analysis. Around $20 \mu \mathrm{L}$ of qPCR mixture containing $2 \mu \mathrm{L}$ of first-strand cDNAs, $10 \mu \mathrm{L}$ of $2 \mathrm{X}$ QuantiTect SYBR Green I Master (Roche, Switzerland), and $0.25 \mathrm{mM}$ of the forward and reverse primers for each gene was used. The qPCR analysis was performed using the Light Cycler 2.0 (Roche Diagnostics, Switzerland). The relative expression of each gene was normalized with glyceraldehyde phosphate dehydrogenase $(\mathrm{GADPH})$ as an internal control. The gene-specific primers used for qPCR analysis are listed in Table S3-4.

\section{Western blot and protein expression}

Total maize leaf protein was extracted using $0.5 \mathrm{~g}$ leaf sample with the $4 \mathrm{~mL}$ of PEB buffer $(100 \mathrm{mM}$ Tris-HCl pH 6.8, $13.8 \mathrm{mM}$ SDS, 1.43\% $\beta-\mathrm{ME}$ (v:v), $1 \mathrm{mM}$ PMSF, $20 \mathrm{mM} \mathrm{NaF}, 20 \%$ Glycerol (v:v)) after grinding samples in liquid nitrogen. The mixture was centrifuged at $18000 \mathrm{~g}$ for $10 \mathrm{~min}$, and the supernates were precipitated at $-20{ }^{\circ} \mathrm{C}$ for $2 \mathrm{~h}$ using an equal volume of pre-cooled acetone. The protein in the precipitate was washed with $80 \%$ pre-cooled acetone at $4{ }^{\circ} \mathrm{C}$ for 5 times by centrifugation at $15,000 \mathrm{~g}$ for $5 \mathrm{~min}$. Finally, the extracted protein was dissolved in $1 \mathrm{~mL}$ of $1 \times \mathrm{PBS}(\mathrm{pH} 7.4$ ) containing $5 \mu \mathrm{L}$ of protease inhibitor cocktail. The protein was immediately heated at $80{ }^{\circ} \mathrm{C}$ for 5 min and separated on $10 \%$ Tri-glycine SDS-PAGE and blotted $1 \mathrm{~h}$ to PVDF using semi-dry or tank transfer. Blots were blocked with $5 \%$ non-fat milk in TBST for $1 \mathrm{~h}$ at room temperature (RT) with continuous stirring. The blots were then incubated with primary antibodies (Anti-PHYA, AS07220; Anti-PHYB AS184170; Anti-PIF4, AS163157; Anti-PIF5, AS122112; Anti-EIN3 AS194273; Agrisera, Sweden) separately at a dilution of 1: 1,000 overnight at room temperature with continuous stirring in TBST buffer. After incubation, the blots were washed for 5 min every 3 times in TBST solution with continuous stirring. The blots were then incubated with secondary antibody (Goat anti-Rabbit IgG (H\&L), HRP conjugated, AS09602, Agrisera, Sweden) diluted to 1:10,000 in TBST buffer for $1 \mathrm{~h}$ at room temperature with continuous stirring. The blot was washed in the same way as described for primary antibody washing. The blots were then developed for $5 \mathrm{~min}$ in a chemiluminescent detection reagent and the respective bands were observed. 


\section{Statistical analysis}

All the obtained data for each parameter were analyzed using SPSS 22.0. The ANOVA technique and Student's $t$-test were used to estimate the variation. All the means were comparable to the 0.05 probability level (d Steel \& Torrie, 1986).

\section{Results}

\section{Maize Leaf Phenotype}

Maize growth and leaf senescence were assessed for 40 days from days after flowering under different light conditions (normal light (NL), partial light (PL), full shade (FS)). Notably, maize leaves maintained significantly more greenness and green leaf area per plant under PL than NL and FS (Fig. 1A-D, Supporting Information Figure S1). Similarly, the data analysis for days to yellowing at the bottom of a leaf, the total number of green leaves, and leaf nitrogen content showed the significant superiority under PL over the leaves under NL and FS conditions. Time taken to the first appearance of the yellow bottom leaves under PL treatment was delayed by 3.6 to 5.9 days with 2.2 to 3.3 more green leaves and 1.1 to 1.4 fold nitrogen uptake than NL and FS (Table 1, Supporting Information Table S1). Interestingly, the first yellow bottom leaf was found on the light side under PL. No difference was observed in the first yellow bottom leaf appearance in two side leaves of NL and FS treatment.

\section{Membrane Lipid Peroxidation and Plasma Membrane Permeability}

To explore the relationship among the leaf aging, lipid peroxidation, cell signaling, and different light environments, reactive oxygen species (Superoxide- $\mathrm{O}_{2}{ }^{-}$and Peroxide- $\mathrm{H}_{2} \mathrm{O}_{2}$ radicals) and malondialdehyde (MDA) was quantified under given conditions at 1,10,20,30, and 40 days after flowering initiation. Quantitative analysis of reactive oxygen species revealed that with increasing leaf age, $\mathrm{H}_{2} \mathrm{O}_{2}$ and $\mathrm{O}_{2}{ }^{-{ }^{-}}$contents increased under all light treatment conditions. Initially, PL significantly induced ROS production during the first ten days, particularly in leaves from the shaded side (PS) compared to PF, NF, and NS (Fig. 2B-C). However, during subsequent days (20-40), the situation reversed, and the maximum production of $\mathrm{H}_{2} \mathrm{O}_{2}$ and $\mathrm{O}_{2}$ was noticed under NL as compared to the minimum production of ROS under PS conditions. Notably, there was no significant difference observed between NF and NS regarding ROS production. Within PL, the PF condition produced significantly more $\operatorname{ROS}\left(14.2 \% \mathrm{H}_{2} \mathrm{O}_{2}, 22.3 \% \mathrm{O}_{2} \cdot{ }^{-}, 6.0 \% \mathrm{MDA}\right)$ than PS, except for the initial ten days of treatment when both treatments behaved the same (Fig. 2B-C). A similar trend was visualized by histochemical staining (Fig. 2A-C). Furthermore, the increased amount of MDA showed that lipid peroxidation followed almost the same trend as ROS production under NF, NS, and PF. Contrarily, the MDA production under PS conditions increased to the maximum $37.6 \mu \mathrm{mol} \mathrm{g} \mathrm{g}^{-1}$ for the first 20 days and then declined significantly to the minimum $30.8 \mu \mathrm{mol} \mathrm{g}{ }^{-1}$ compared to NF, NS, and PF (Fig. 2D).

To investigate the difference in ROS detoxification, we analyzed the activity of the three most critical antioxidant enzymes (SOD, POD, CAT) that scavenge excessive ROS. The results showed a highly significant increase in the activity of SOD for the first 20 days and POD and CAT for the first ten days under PS after that it started to decline (Fig. 2E-G). On the other hand, there were no significant differences observed between NF and NS despite the increase in activity (POD, CAT up to 30 days; SOD up to 20 days).

\section{Photosynthetic Characteristics}

We investigated whether the delay in leaf senescence was related to improved photosynthetic performance in maize plants. Our results revealed that the two sides of maize under partial light (PF, PS) conditions show significantly different responses as compared to those which were exposed to normal light (NF, NS). Partial light-induced greater photosynthetic activity (increasing $5.3 \%$ of photosynthetic rate $\left(P_{n}\right), 47.1 \%$ stomatal conductance $\left(\mathrm{G}_{\mathrm{s}}\right)$, and $4.0 \%$ of transpiration rate $\left.\left(T_{r}\right)\right)$ and increased photosynthetic pigments as compared to NL (Table 2). Under PL, the PS increased $10.3 \%$ and $13.3 \%$ in photosynthetic activity and Chlb content at the later stage (days from 20 to 40), respectively, while PF caused a rise in Chla content and Chla/Chlb ratio. Contrarily, under normal light conditions, the two treatments (NF, NS) did not show a 
significant difference in photosynthesis rate and photosynthetic pigments accumulation (Table 2; Supporting Information Figure S3).

\section{Sugars and Starch Activities and Change in ${ }^{13} \mathrm{C}$ in Maize}

Different light environments significantly regulated the various sugars and starch levels in maize leaves (Fig. 3 ). Generally, all the treatments showed a similar trend of initial increase up to 10-20 days followed by a decline in later days, except the initial decrease of soluble starch content and sucrose synthase activity in PS leaves. However, partial light conditions significantly induced the content of sucrose, soluble sugar, and relative enzymes than normal light conditions (days from 20 to 40). Notably, unlike NL treatments (NF and NS), PL treatments (PF and PS) differed significantly. PS conditions significantly increased 2.0, 1.6, 1.4, 1.2 fold activities of $\alpha$-amylase, $\beta$-amylase, starch phosphorylase, and DBE than PF, while the similar activities of all enzymes were observed in NF and NS. Interestingly, despite the initial highest content under PF conditions, PS conditions retained the highest amount of soluble sugars, soluble starch, and sucrose after 20 days. Furthermore, sucrose synthase and sucrose phosphate activities were highest in PF than PS, NF, and NS. These results may indicate that PS leaves degrade starch and PF leaves enhance sucrose synthesis to make up for the deficiency of sugar caused by shading in the early stage, and both PS and PF leaves increase the supply of sugar in the later stage by delaying senescence.

To determine whether an increase in carbon activity played a major role in delaying leaf senescence in maize, we measured the activities of ${ }^{13} \mathrm{C}$ movement and location in maize plants under different light treatments. We found that ${ }^{13} \mathrm{C}$ abundance significantly increased by $16.9 \%$ in PL than in NL and $38.1 \%$ in PS than in PF on day 1 up to day 10, respectively. Decrease $i^{13} \mathrm{C}$ abundance started from day 20 up to day 40 without significant differences in their levels under PL and NL (Fig. 4A). The abundance of ${ }^{13} \mathrm{C}$ in different leaves showed that partial shade increased ${ }^{13} \mathrm{C}$ accumulation in the ML (middle leaves) and BL (bottom leaves) than in the TL (top leaves) on day 1 before it started to decrease from day 10 up to day 40 (Fig. 4B). Different light treatments on different maize leaves showed that SM (middle leaves of shade side) and SB (bottom leaves of shade side) increased $57.1 \%$ and $20.8 \%$ of ${ }^{13} \mathrm{C}$ abundance under PL before day 10 compared to NL before starting to decrease from day 20 up to day 40 (Fig. 4C). Analysis of different parts of maize plants showed that ${ }^{13} \mathrm{C}$ abundance increased by $18.2 \%$ in the ear of PL leaves compared to NL with the senescence progress from day 20 up to day 40 . These increases mainly came from roots and stem, compared to $\mathrm{NL},{ }^{13} \mathrm{C}$ abundance reduced by $34.7 \%$ and $7.8 \%$ in roots and stem of PL, respectively (Fig. 4D). Interestingly, ${ }^{13} \mathrm{C}$ abundance in the stem decreased more than in other tissues in the later stage (days from 20 to 40), even in the leaves. The above results showed that carbon supplement in the middle and bottom leaves of the shade side at the early period and mobilization of various organs (especially reducing carbon accumulation in stem and roots) to promote carbon accumulation in-ears at the later period are the key characteristics of improving carbon utilization in maize under partial shade.

\section{Phytohormones and related genes expression in Maize Leaves}

Plant hormones regulate various processes, including leaf senescence. Therefore, to estimate the role of phytohormones in delaying leaf senescence under different light conditions, we estimated the contents of IAA, $\mathrm{GA}_{3}, \mathrm{ABA}$, and ethylene (Fig. 5). Generally, under all the treatments, the phytohormones ABA, ethylene, and IAA accumulation increased up to 20 days while $\mathrm{GA}_{3}$ accumulation decreased, except under PS, in which it significantly increased for the first ten days followed by a sharp decline for the next 10 days and again a subsequent increase in last 20 days. Notably, the initial rise (days from 0 to 20 ) in IAA, GA, ABA, and ethylene contents in PS was 1.2, 1.4, 1.4, 1.1, 1.3, 1.2, 1.4, 1.2 and 1.3, 1.2, 1.3, 1.1 fold significantly higher than PF, NF, and NS. However, unlike NL treatment, the amount of ABA and ethylene declined under PS and PF in the last 20 days, and treatment PS showed the minimum $0.79 \mathrm{mg} \mathrm{g}^{-1}$ of $\mathrm{ABA}$ and $15.9 \mathrm{ng} \mathrm{\textrm {L } ^ { - 1 }}$ ethylene at day 40. Furthermore, all the treatments showed the same decreasing trend for IAA after day 20, yet, the treatment PS retained a significantly higher amount of IAA than PF, NF, and NS. Overall, the results revealed that the level of various phytohormones significantly increased under PL conditions for the first 20 days after that they started to decline until day 40 . However, the NL conditions did not induce any significant changes between the two sides in the accumulation of studied 
phytohormones. The transcription levels of $Z m A B I 5.1$ and $Z m E I N 3.1$ were down-regulated notably under PL than NL treatment, while a slight up-regulation of ZmEIN3.1 was found in PS before day 20 (Fig.6A). However, the minimum expression levels of $Z m A B I 5.1$ and $Z m E I N 3.1$ were found in PF leaves, the same results were observed in protein expression of EIN3 (Fig.6B). After that ZmABI5.1 and ZmEIN3.1 under PL started to decline compared to NL treatment, where their expression was significantly increased between days 20 and 30 days, respectively, before declining in the last ten days.

\section{Expression of light signals genes, nitrate and sugar transporter genes, and SAGs in maize}

We wondered whether the improved performance of maize leaves under PS compared to the PF resulted from increased transcript abundance of maize-related SAGs. To address this question, the effect of different light treatments on expression levels of ZmPHYA1b,ZmPHYB1c, ZmPIF4.1, and ZmPIF5.1 using qRTPCR analysis was tested. The results showed that the expression levels of ZmPHYA1b, ZmPIF4.1, and $Z m P I F 5.1$ were significantly up-regulated on day 10 to day 20 then started to decrease up to day 40 in PS leaves under PL (Fig. 6A), while significantly down-regulated in PF leaves in all process. There were no significant differences inZmPHYA1b,ZmPIF4. 1, and ZmPIF5.1 expression levels in NF and NS. Except for PIF4, similar results for PHYA and PIF5 protein expression were also observed. PF leaves significantly increased the $Z m P H Y B 1 c$ expression level from day 1 up to day 20; after that, it started to decrease. Although $Z m P H Y B 1 c$ expression levels increased in NF and NS treatments, however, their expression levels were not significantly different. In contrast, PS treatment significantly down-regulated the $Z m P H Y B 1 c$ expression level (Fig. 6B).

Carbon and nitrogen balance in plant cells is important in measuring plant senescence activity. Expression analysis of $Z m P a O, Z m S A G 2$, and $Z m S A G 12.1$ showed an up-regulated level of the transcript after ten days of PS treatment, indicating that senescence was induced in PS leaves. However, a significant decrease in transcripts was observed in the next 30 days in PS compared to NF and NS. In contrast, the maximum expression peaks for ZmNRT1.1a, ZmSUT1a, and ZmSWEET11.1 were observed in PF and PS after ten days of partial shade treatment in leaves. Under PL treatment, the transcription levels of ZmNRT1.1a, ZmSUT1a, and ZmSWEET11.1 were found higher than in NL. No significant difference in transcript levels was observed in NF and NS leaves (Fig. 7).

\section{Yield and Yield Components}

There are no significant differences in seed dry matter accumulation and yield components between PL and NL treatment (Fig. 8 and Table 3). Again, PL significantly increased seed dry matter accumulation starting from the first 25 days, and peaked at 30 days, then declined until day 40. NL also increased seed dry matter accumulation from day 5 to a peak at 25, then reduced until day 40 (Fig. 8). These results indicated that partial light ( $80 \%$ transmittance of normal light) can delay leaf senescence for almost 5 days but get the same yield of normal light, which means it's possible to use a narrow-wide-row planting pattern to obtain the same yield with monoculture but save more land for other crops growth.

\section{Discussion}

Existing literature has revealed that shading increases leaf senescence, affects plant growth, and decreases crop yield (Gindaba \& Midgley, 2005; Spundova et al., 2005). However, different shading patterns, exposure time, the intensity of shade, and tissue position will lead to varied responses by a plant. Until now, the mechanism involved in how partial shading delays leaf senescence in maize remains unclear. In our previous study, the phenotype of delaying maize leaf senescence under narrow-wide row planting patterns in the field was investigated partially (Feng et al., 2020). The cultivation patterns in the field are shown in Supporting Information Figure S4 for a better understanding. Therefore, the present study aimed at providing a detailed mechanism underlying how partial shading delays leaf senescence in maize. Our work is the first report about the synergy in response to shade between two side leaves in maize and how partial shading decreases leaf senescence in maize through increased photosynthetic performance and increased carbon fixation, which finally balances maize yield (Table 2,3). Our phenotypic data, photosynthetic efficiency, phytohormones synthesis, antioxidants enzyme activity, plant sugar accumulation, carbon activity, and gene expression 
analysis provided evidence that the partial shading in maize enhances photosynthetic carbon fixation, which delays the leaf senescence resulting in an extended grain-filling period. The phenotypic response of maize plants to different light intensity treatments suggested that full shade induced leaves senescence rapidly compared to partial shading (Supporting Information Figure S1, Table S1), which is consistent with a previous report (Spundova et al., 2005). Partial shade delayed senescence more significantly than the normal light, so we used the normal light treatment as a control to explain the mechanism of partial shade induced delayed senescence in maize.

\section{Partial shading improves photosynthetic performance by increasing leaf greenness and delaying LS}

It has previously been reported that plants exhibit different metabolic strategies in different light intensities (Keech et al., 2007). Maize leaves are highly sensitive to slight changes in light intensity, and any decrease in light intensity affects photosynthetic performance (Feng et al., 2019), which results in a change in leaf greenness, as shown in the current study. We attribute the delayed senescence in maize leaves as a contributor to increased plant photosynthetic capacity and carbon balance. The results indicate that partial shading delays the leaf senescence process in maize compared to NL, possibly via an enhanced photosynthetic process. However, the light interception by the whole plant is also important in the delayed leaf senescence process. For instance, our results of different partial shading degrees showed that $20 \%$ shading would delay leaf senescence, maintain leaf greenness and nitrogen content, prolong the senescence time of bottom leaves, and increase the leaf area (Supporting Information Figure S5, Table S2).

Improved photosynthetic performance is required for balanced growth in plants. In the present study, partial shade remarkably increased maize photosynthetic ability compared to full shade. Evidence has demonstrated that shade changes a plant's micro-climate, which disrupts a plant's photosynthetic performance, growth activity, and reduced yield (Gindaba \& Midgley, 2005), while the right amount of shading improves plant growth and photosynthetic performance (Han et al., 2018). Consistent with the present study data, NL significantly reduced photosynthetic performance in maize plants, while partial shading improved the photosynthetic performance in maize plants. We observed that all the photosynthetic characteristics, Chl b, and nitrogen content were increased under partial shade (Fig.1, Supporting Information Figure S3). According to the results (Hachiya \& Noguchi, 2011), the high transcription of nitrogen transporter geneZmNRT1.1a may maintain the nitrogen content and chlorophyll protein stability in PS leaves. Furthermore, the expression of chlorophyll degradation-related genes $(\mathrm{ZmPaO})$ increased at first ten days then stayed unchanged in PS, however in NL treatment, the expression level constantly increased during the whole experimental period, indicating leaves chlorophyll degradation in PS was reversed but continued to rise in NL (Fig. 7). Chlorophyll content and degradation process were positively correlated with aging senescence. We speculate that a possible mechanism is used by partial shade to enhance delay in leaf senescence in maize. We hypothesized that the improvement in the photosynthetic performance during the partial shade treatment might result from enhancement in plant hormonal balance under the partial treatment (Clarke et al., 2009; Wang et al., 2010). Others also reported that delay in leaf senescence could improve plant photosynthetic performance, which could, in turn, increase plant yield (Gregersen, 2011), which is consistent with our results (Table 3). Together, these results suggest that partial shade delays leaf senescence in maize by enhancing the photosynthetic rate and inhibiting chlorophyll degradation.

\section{How Partial Shade Coordinates Phytohormones homeostasis to Regulate Leaf Senescence?}

Phytohormones and their related genes regulate plant growth and development under various stresses (Bawa et al., 2020a; Bawa et al., 2020b; Tang et al., 2019). Indeed, all major plant hormones have been reported to play an important role in leaf senescence regulation (Schippers et al., 2007) by altering the time of agerelated changes and interacting with the prevailing environmental conditions, thus influencing the speed of the overall senescence process (Jibran et al., 2013). Similarly, in the present study, we hypothesized that different light regimes might influence the hormonal regulations between the two sides of the maize plant, impacting leaf senescence. For instance, phytohormones like ethylene, abscisic acid (ABA), and salicylic acid (SA) accelerate the senescence process in contrast accumulation of auxin, gibberellin, and cytokinin 
delay senescence (Guo \& GAN, 2012; Jibran et al., 2013). Previously, increased accumulation of some plant hormones such as IAA and $\mathrm{GA}_{3}$ under slight shading has been reported as growth promotion indicators (Han et al., 2018). Consistent with these findings, our results showed that the partial light conditions induced significant accumulation of IAA, ABA, GA 3 , and ethylene, specifically in PS leaves. The IAA content in PF leaves also increased; suggesting that some key factors might regulate phytohormone balance and limit leaf senescence in PS treatment (Fig. 9). PIF4 binds promoters of TAA1 , CYP79B2, and YUCCA8 genes to promote auxin biosynthesis at high temperatures (Sun et al., 2012; Wang et al., 2017a). In the current study, may be a similar mechanism of ZmPIF4 controls the IAA level in maize leaves under PS treatment. PIF4 and PIF5 regulated GA biosynthesis via a circadian clock factor ELF3 as loss of ELF3 activity caused GA accumulation. Moreover, PIF4 is also involved in activating transcription factors EIN3 and ABI5 to regulate leaf senescence. In the present study, PIF5 and not PIF4 might play a key role in maintaining phytohormone balance because only PIF5 was strongly induced by the PS treatment (Fig. 6B). Another protein expression data of full shade leaves showed that continuous shading could significantly influence the expression of PHYA and EIN3 that leads to leaf senescence (Supporting Information Figure S6). However, the senescence inducing hormones (ABA and ethylene) decreased significantly during the succeeding days which could be a reason for the delayed leaf senescence under the partial light conditions.

Photoreceptors recognize the light conditions in plants, and as a component of light signaling, they are associated with leaf senescence (Kim et al., 2017). In this perspective, identifying some major transcription factors (TFs) that play a crucial role in leaf senescence through TFs-mediated senescence regulations has enhanced the importance of TFs-mediated senescence regulation. Therefore, we investigated the expression of several transcription factors that are involved in light signaling and phytohormone responses like ZmPHYA1b (Zea maize Phytchrome A1 b),ZmPIF4.1 (Zea maize Phytochrome Interacting factor 4.1),ZmPIF5.1, ZmEIN3.1 (Ethylene Insensitive 3),ZmABI5.1 (ABA Insensitive 5) and SAG (Senescence associated genes) to verify their contribution in the regulation of leaf senescence under the different light regimes in maize plants. Several reports have suggested the involvement of PIFs in dark-induced and developmental senescence as they transduce light information to primary senescence regulators (Kim et al., 2017). PIF4/PIF5 acts in the signaling pathways of two senescence-promoting hormones, ethylene and abscisic acid, by directly activating the expression of EIN3, ABI5, and EEL (Sakuraba et al., 2014). Similarly, in our study, during the first ten days under partial light conditions, the PS leaves of maize plants showed significant upregulation of $Z m P H Y A 1 b$ , ZmPIF4.1, and ZmPIF5.1, ZmABI5.1, and ZmEIN3.1 genes (Fig. 6A). Here, PIF4 protein was not expressed in NL and PL treatments. However, in FS, the expression of PIF4 was significantly induced by early full shading. The same results were found in PHYA, PIF5, EIN3, indicated heavy shade would certainly lead to rapid leaf senescence (Fig. 6B). Contrarily, their expression was suppressed in the PF leaves compared to NF, NS, and PS. It shows that the leaves under PF conditions compensated the leaves on the other side of the maize plant to counter the influence of shading which could be a reason for delayed leaf senescence. In agreement with our results, different studies reported the activation of senescence-related genes in $A$. thaliana under partial shading (Brouwer et al., 2014). However, our research found that heterogenous shading under PL conditions induced a regulatory mechanism between the two side leaves. The PF leaves balanced the initial increase of senescence regulators in PS leaves.

Several senescence-associated genes (SAGs) have been identified in Arabidopsis, wheat, rice, and maize that have been linked to the complicated and highly regulated process of leaf senescence (Li et al., 2014; Wu et al., 2016). Therefore, to further verify the information revealed through phytohormone signaling regulation and expression of relevant transcription factors, we quantified maize SAGs. Notably, the reduced expression of ZmSAG2and ZmSAG12 in PS and significant reduction after an initial increase in the first ten days under partial light conditions suggested a synergy between the two side leaves. This observation verified the delayed leaf senescence under partial light conditions in maize (Fig.7). Furthermore, in agreement with our hypothesis, seed dry matter accumulation increased from day 5 up to day 25 under NL. In contrast, partial shading increased dry seed matter accumulation from day 5 up to day 35 (Fig. 8), which could be due to increased leaf greenness under partial light conditions. Collectively, it could be displayed from the hormonal signaling and expression pattern of senescence-related TFs that the decrease in light intensity improved the 
growth response and greenness of maize leaves due to the compensatory interaction between the two lateral sides of the maize plant under heterogeneous light conditions.

\section{The Regulation of ROSs and Antioxidant Enzymes under Partial Shade}

Plants possess a strong antioxidant system that regulates membrane oxidation by scavenging reactive oxygen species (ROS) (Gill \& Tuteja, 2010). An increase in oxidative processes in plants leads to the production of ROS. This oxidative damage subsequently causes physiological changes and cell membrane damage in plants (Mutlu et al., 2016). However, the upregulation of antioxidant enzymes directly compensates for or decreases the effect of the ROS in plants, which is consistent with the present study. Here, NL increased the activities of ROS than partial shading, suggesting that cell membrane performance was reduced in NL (Fig. 2). In partial shade treatment, $Z m P H Y A 1 b$ gene expression was significantly increased in PS but decreased in PF. However, $Z m P H Y B 1 c$ expression was opposite to $Z m P H Y A 1 b$ (Fig. 7). The increased expression of ZmphyA1b in PS negatively regulated FHY3 and FAR1 and reduced ROS accumulation. It is reported that the disruption of phytochrome A (PHYA) the crucial components far-red elongated hypocotyls 3 (FHY3) and far-red-impaired response 1 (FAR1) caused light-induced precocious leaf senescence and increased sensitivity to oxidative stress (Ma et al., 2016; Wang \& Wang, 2015). Recent research reported that PHYB regulated systemic stomatal aperture closure responses and high ROS accumulation in excess light (Devireddy et al., 2020). ZmPHYB1cdownregulation in PS also inhibited the ROS level. Increased antioxidant activities were observed in partial shading than NL (Fig. 2). These results agreed with previous studies where partial shading increased the activity of antioxidant enzymes, which subsequently reduced the lipid peroxidation, which delayed the senescence process in winter wheat (Xu et al., 2016). However, our results presented a new insight into maize leaves behavior and mutual interaction under heterogenous shading conditions. Interestingly, within PL, partial shading significantly boosted the antioxidative response of maize leaves that protected the leaves on both sides and encountered the initial rise in oxidative stress and membrane damage effectively. Recently, a study reported drought tolerance and improved growth parameters of preshaded leaves due to the upregulation of antioxidative response and osmoregulation (Asghar et al., 2020). Similarly, the results in our study suggested that partial light-induced moderate oxidative stress triggered the antioxidative response and, as a result, improved the growth of maize plants which resulted in delayed leaf senescence.

\section{Partial Shade Balances Sucrose-Starch Metabolism via Compensation by PF Leaves}

Plants are autotrophic organisms, and sugar metabolism in plants represents their growth regulation, stress tolerance response, and productivity. Therefore, monitoring carbohydrate status and metabolic activities in plants could be crucial for estimating the influence of various light conditions on the production and allocation of photoassimilates. The two most important carbohydrate pools that result from carbon assimilation during photosynthesis include the storage pool (starch) and export pool (sucrose). Sucrose, an important output of photosynthesis, is synthesized by the sucrose phosphate synthase (SPS). In contrast, sucrose synthase (SS) is involved in catalysis, both the degradation and synthesis of sucrose in plants (Du et al., 2020). Similarly, starch is the main storage carbohydrate in plants. Its metabolism through amylases $(\alpha$ and $\beta$ ) and debranching enzymes (DBEI, DBEIIa, and DBEIIb) are crucial for stress response and sugar biosynthesis under stress conditions (Du et al., 2020; Stitt \& Zeeman, 2012; Streb \& Zeeman, 2012). Previously, researchers reported the increased transportation and starvation of sugar under environmental stress that promotes plant growth and enhances stress capacity (Lemoine et al., 2013; Paparelli et al., 2013). Our investigations demonstrated that partial light conditions (PL) enhanced the soluble sugar and sucrose levels than normal light conditions (NL) (Fig. 4). We speculated the mutual balancing and compensation of sugar levels between the two sides of leaves (PF and PS) under partial light conditions, which might be a reason for delayed leaf senescence under PL conditions. It has been extensively reported that starch is hydrolyzed into sugar in response to stress (Amiard et al., 2005; Burke, 2007; Thalmann et al., 2016). Similarly, partial shading (PS) significantly induced starch degrading enzymes during the first ten days after flowering. This decline in soluble starch content and sucrose synthase activity in PL leaves triggered the sucrose synthesis in PF leaves and its transport towards PS leaves to compensate for the initial breakdown of starch. Fur- 
thermore, light receptor PHYB has been reported to promote starch accumulation (Han et al., 2017; Sun et al., 2017). Consistent with these reports, our idea showed that the increased expression of ZmPHYB1c in $\mathrm{PF}$ enhanced starch and sugar biosynthesis through starch degradation in PF, which compensated PS leaves. This mechanism helped maintain leaf greenness in maize under partial shading (Li et al., 2020). It probably created a synergy between the two side leaves that increased SPS and SS activity in PF leaves to maintain the sucrose and starch content in PS leaves, which helped in delaying senescence. On the other hand, the decrease in photosynthetic rate preceded leaf yellowing under all conditions, which might have induced leaf senescence through decreased sugar levels (Quirino et al., 2000). Similar results were reported in a previous report in which sugar degradation in complete shading resulted in leaf yellowing and increased relative electrolyte leakage (van Doorn, 2008).

Subsequently, we traced the translocation through the carbon labeling to verify the regulation of sugar synthesis between PF and PS, and the distribution of photoassimilates under partial and normal light conditions. A significant increase of ${ }^{13} \mathrm{C}$ abundance in the leaves of partial shading rather than normal light in day 1 to day 10 indicated the higher sugar production under PL (Fig. 4). A similar situation for a maximum peak of ${ }^{13} \mathrm{C}$ was observed in ryegrass shoot day 1 (Butler et al., 2004). In addition, ${ }^{13} \mathrm{C}$ abundance in different parts of the maize plant was significantly elevated in the middle and bottom leaves in PL at day 1 under partial shading (Peuke et al., 2001). Combined with the evidence from increased $P_{n}$ (Table 2), up-regulated and higher contribution of soluble sugar and sucrose synthesis by PF than PS (Fig. 3A, C-E) and, the higher ${ }^{13} \mathrm{C}$ abundance in the stem during initial ten days and then in-ear during late 30 days (Fig. 4) under PL inferred that partial shade enhanced the photosynthetic carbon fixation function of PF leaves. Furthermore, we confirmed that about $5 \%$ of ${ }^{13} \mathrm{C}$ was transferred from $\mathrm{PF}$ into PS, and $70 \%$ of the ${ }^{13} \mathrm{C}$ was supplied to the middle and lower leaves when the ear was not fully formed after flowering. It is shown that an increase in sugar level and balance of sugar transfer between the PF and PS leaves helped the leaves to maintain greenness under a partial light environment.

To further verify this hypothesis at the molecular level, we analyzed the expression pattern of sugar transporter genes, i. e., SUT, that help to diffuse sucrose into phloem through the apoplast pathway (Riesmeier et al., 1992; Sauer, 2007). Another essential sucrose transporter, "SWEET", transfers the sucrose from parenchyma to apoplast (Chen et al., 2012). Keeping in view the role of SUT and SWEET genes in sucrose transport, we observed the expression pattern of ZmSUT1a and ZmSWEET11.1 under normal and partial light conditions. In line with our speculation and pre-mentioned results, both genes (ZmSUT1a and $Z m S W E E T 11.1)$ showed significantly higher expression under the PL than NL conditions. Interestingly, the ZmSUT1a and ZmSWEET11.1 were up-regulated considerably during the first ten days in PF leaves. However, from day $25^{\text {th }}$ and onward, the two genes showed significantly higher expression in PS leaves, indicating that sugar transport was increased towards the PS leaves. Overall, it verifies our hypothesis about the balancing of sugar in PS leaves by PF leaves under shading conditions that could delay senescence in both side leaves, which increases the outflow of sugar into the ear, as seen from the delayed grain filling period (Fig. 4D, 6C, 8). We suggest that partial shade stimulation may have enhanced the photosynthetic carbon sequestration function of PF leaves to compensate for the carbon assimilation in PS leaves and improved carbon balance and resistance on both sides. Altogether, these results suggested an increase in sugar levels and sugar balance between PF and PS was required for the delayed leaf senescence in maize.

\section{Conclusions}

In conclusion, the present findings demonstrated that partial light conditions improved communication in maize leaves between light-side (PF) and shade-side (PS). The changes of light signals and phytohormone signals (e. g., light sensor phytochrome A and phytochrome B and phytochrome interaction factor in both light-side and shade-side maize leaves under partial shade regulated IAA and GA biosynthesis which balanced the senescence hormone ABA and ETH. Besides, the enhanced antioxidant enzymes (e.g., POD, SOD, CAT) reduced cell membrane lipid peroxidation and ROS level. The down-regulated $\mathrm{ZmPaO}$ gene (pheophorbide an oxygenase) inhibited chlorophyll degradation, and improved maize leaves photosynthetic carbon fixation and sugar biosynthesis in light-side leaves. In the earlier ten days from flowering, more ${ }^{13} \mathrm{C}$ abundance and soluble 
sugar were observed in shade-side leaves, while starch was degraded through increasing $\alpha$-amylase, $\beta$-amylase, phosphorylase activities indicating compensatory effects between light-side and shade-side leaves. Moreover, the high transcription level of ZmNRT1.1,ZmSUT1a, and Zmsweet11.1 and improved net photosynthesis were found in light-side leaves, which strongly and ulteriorly illustrated the above conclusion. Compared to $\mathrm{NL}$, the increase in maize leaf area, greenness, chlorophyll, and decreasing ABA and ETH level, senescence genes, ZmSAG2 and ZmSAG12.1 under PL in the last 20 days showed that the aging process of partial light leaves was delayed. As an adaptive response of carbon fixation, more nitrogen uptake from roots improved leaves totals N content in PL. Finally, the seed's dry matter peak was also delayed in PL. Still, no significant difference in yield between NL and PL was observed, demonstrating that partial shade improved the utilization of light resources via delaying maize leaf senescence (Fig. 9). This mechanism lays a foundation for a better understanding of using the senescence characteristics of the maize-based intercropping system to improve high yield in areas with more people and less land.

\section{Acknowledgments}

This work was supported by the National Natural Science Foundation of China (32071963), a grant from the International S \& T Cooperation Projects of Sichuan Province (2020YFH0126), and the Program on Industrial Technology System of National Soybean (CARS-04-PS19).

\section{References}

Amiard, V., Mueh, K. E., Demmig-Adams, B., Ebbert, V., Turgeon, R., \& Adams, W. W. (2005). Anatomical and photosynthetic acclimation to the light environment in species with differing mechanisms of phloem loading. Proceedings of the National Academy of Sciences, USA, 102, 12968-12973.

Asghar, M. A., Du, J., Jiang, H., Li, Y., Sun, X., Shang, J., Liu, J., Liu, W., Imran, S., Iqbal, N., Ahmad, B., Hussain, S., Yu, L., Liu, C., \& Yang, W. (2020). Shade pretreatment enhanced drought resistance of soybean. Environmental and Experimental Botany, 171, 103952.

Barreiro, R., Guiamét, J. J., Beltrano, J., \& Montaldi, E. R. (1992). Regulation of the photosynthetic capacity of primary bean leaves by the red:far-red ratio and photosynthetic photon flux density of incident light.Physiologia Plantarum, 85, 97-101.

Bawa, G., Feng, L., Chen, G., Chen, H., Hu, Y., Pu, T., Cheng, Y., Shi, J., Xiao, T., Zhou, W., Yong, T., Sun, X., Yang, F., Yang, W., \& Wang, X. (2020a). Gibberellins and auxin regulate soybean hypocotyl elongation under low light and high-temperature interaction. Physiologia Plantarum,170, 345-356.

Bawa, G., Feng, L., Shi, J., Chen, G., Cheng, Y., Luo, J., Wu, W., Ngoke, B., Cheng, P., Tang, Z., Pu, T., Liu, J., Liu, W., Yong, T., Du, J., Yang, W., \& Wang, X. (2020b). Evidence that melatonin promotes soybean seedlings growth from low-temperature stress by mediating plant mineral elements and genes involved in the antioxidant pathway. Functional Plant Biology, 47, 815-824.

Bawa, G., Feng, L., Yan, L., Du, Y., Shang, J., Sun, X., Wang, X., Yu, L., Liu, C., Yang, W., \& Du, J. (2019). Pre-treatment of salicylic acid enhances resistance of soybean seedlings to Fusarium solani. Plant Molecular Biology,101, 315-323.

Bennett, E. J., Roberts, J. A., \& Wagstaff, C. (2014). Use of Mutants to Dissect the Role of Ethylene Signalling in Organ Senescence and the Regulation of Yield in Arabidopsis thaliana. Journal of Plant Growth Regulation,33, 56-65.

Boonman, A., Anten, N. P., Dueck, T. A., Jordi, W. J., van der Werf, A., Voesenek, L. A., \& Pons, T. L. (2006). Functional significance of shade-induced leaf senescence in dense canopies: an experimental test using transgenic tobacco.American Naturalist, 168, 597-607.

Brouwer, B., Gardeström, P., \& Keech, O. (2014). In response to partial plant shading, the lack of phytochrome A does not directly induce leaf senescence but alters the fine-tuning of chlorophyll biosynthesis. Journal of Experimental Botany,65 , 4037-4049. 
Brouwer, B., Ziolkowska, A., Bagard, M., Keech, O., \& Gardeström, P. (2012). The impact of light intensity on shade-induced leaf senescence. Plant Cell \& Environment,35 , 1084-1098.

Buchanan-Wollaston, V., Earl, S., Harrison, E., Mathas, E., Navabpour, S., Page, T., \& Pink, D. (2003). The molecular analysis of leaf senescence-a genomics approach.Plant Biotechnology Journal, 1 , 3-22.

Burke, J. J. (2007). Evaluation of source leaf responses to water-deficit stresses in cotton using a novel stress bioassay. Plant Physiology, 143 , 108-121.

Butler, J., Bottomley, P., Griffith, S., \& Myrold, D. (2004). Distribution and turnover of recently fixed photosynthate in ryegrass rhizospheres. Soil Biology and Biochemistry, 36 , 371-382.

Cao, Y., Zhang, Z. W., Xue, L. W., Du, J. B., Shang, J., Xu, F., Yuan, S., \& Lin, H. H. (2009). Lack of salicylic acid in Arabidopsis protects plants against moderate salt stress. Z Naturforsch C J Biosci, 64 , 231-238.

Chen, G., Chen, H., Shi, K., Raza, M., Bawa, G., Sun, X., Pu, T., Yong, T., Weiguo, L., Liu, J., Du, J., Yang, F., Yang, W., \& Wang, X. (2020). Heterogeneous Light Conditions Reduce the Assimilate Translocation Towards Maize Ears. Plants,9 , 987.

Chen, L. Q., Qu, X. Q., Hou, B. H., Sosso, D., Osorio, S., Fernie, A. R., \& Frommer, W. B. (2012). Sucrose efflux mediated by SWEET proteins as a key step for phloem transport.Science, 335, 207-211.

Clarke, S. M., Cristescu, S. M., Miersch, O., Harren, F. J., Wasternack, C., \& Mur, L. A. (2009). Jasmonates act with salicylic acid to confer basal thermotolerance in Arabidopsis thaliana. New Phytologist, 182 , 175187.

d Steel, R. G., \& Torrie, J. H. (1986). Principles and procedures of statistics: a biometrical approach : McGraw-Hill.

Devireddy, A. R., Liscum, E., \& Mittler, R. (2020). Phytochrome B is required for systemic stomatal responses and ROS signaling during light stress. Plant Physiology .

Dobrev, P. I., \& Kamínek, M. (2002). Fast and efficient separation of cytokinins from auxin and abscisic acid and their purification using mixed-mode solid-phase extraction. J Chromatogr A, 950, 21-29.

Du, Y., Zhao, Q., Chen, L., Yao, X., Zhang, W., Zhang, B., \& Xie, F. (2020). Effect of drought stress on sugar metabolism in leaves and roots of soybean seedlings. Plant Physiology and Biochemistry, 146, 1-12.

Ellis, C. M., Nagpal, P., Young, J. C., Hagen, G., Guilfoyle, T. J., \& Reed, J. W. (2005). AUXIN RESPONSE FACTOR1 and AUXIN RESPONSE FACTOR2 regulate senescence and floral organ abscission in Arabidopsis thaliana. Development, 132, 4563-4574.

Elstner, E. F., \& Heupel, A. (1976). Inhibition of nitrite formation from hydroxylammoniumchloride: a simple assay for superoxide dismutase. Analytical Biochemistry,70 , 616-620.

Feng, L., Raza, M. A., Li, Z., Chen, Y., Khalid, M. H. B., Du, J., Liu, W., Wu, X., Song, C., Yu, L., Zhang, Z., Yuan, S., Yang, W., \& Yang, F. (2019). The Influence of Light Intensity and Leaf Movement on Photosynthesis Characteristics and Carbon Balance of Soybean. Frontiers in plant science, 9 , 1952.

Feng, L., Raza, M. A., Shi, J., Ansar, M., Titriku, J. K., Meraj, T. A., Shah, G. A., Ahmed, Z., Saleem, A., Liu, W., Wang, X., Yong, T., Yuan, S., Yang, F., \& Yang, W. (2020). Delayed maize leaf senescence increases the land equivalent ratio of maize soybean relay intercropping system. European Journal of Agronomy, 118 , 126092 .

Gill, S. S., \& Tuteja, N. (2010). Reactive oxygen species and antioxidant machinery in abiotic stress tolerance in crop plants. Plant Physiol Biochem, 48 , 909-930. 
Gindaba, J., \& Midgley, S. (2005). Comparative Effects of Evaporative Cooling, Kaolin Particle Film, and Shade Net on Sunburn and Fruit Quality in Apples. HortScience: a publication of the American Society for Horticultural Science, $\mathbf{4 0}$, 592-596.

Grbic, V., \& Bleecker, A. B. (2010). Ethylene regulates the timing of leaf senescence in Arabidopsis.Plant Journal, 8 , 595-602.

Gregersen. (2011). Senescence and Nutrient Remobilization in Crop Plants. In The Molecular and Physiological Basis of Nutrient Use Efficiency in Crops (pp. 83-102).

Guo, Y., \& GAN, S. S. (2012). Convergence and divergence in gene expression profiles induced by leaf senescence and 27 senescence-promoting hormonal, pathological and environmental stress treatments. Plant, Cell $\mathscr{E}$ Environment,35, 644-655.

Hachiya, T., \& Noguchi, K. (2011). Mutation of NRT1.1 enhances ammonium/low pH-tolerance in Arabiopsis thaliana. Plant Signaling \& Behavior, 6 , 706-708.

Han, C., Wang, Q., Zhang, H., Wang, S., Song, H., Hao, J., \& Dong, H. (2018). Light shading improves the yield and quality of seed in oil-seed peony (Paeonia ostii Feng Dan).Journal of Integrative Agriculture, 017 , 1631-1640.

Han, X., Tohge, T., Lalor, P., Dockery, P., Devaney, N., Esteves-Ferreira, A. A., Fernie, A. R., \& Sulpice, R. (2017). Phytochrome A and B Regulate Primary Metabolism in Arabidopsis Leaves in Response to Light. Frontiers in plant science, $\mathbf{8}, 1394$.

Huang, S. R., Du, J. B., Wang, X. C., Sun, X., \& Yang, W. Y. (2019). Involvement of carbohydrates in long-term light-dependent systemic regulation on photosynthesis of maize under light heterogeneity. Plant Signaling \& Behavior,14, e1629266.

Jiang, Y., Liang, G., Yang, S., \& Yu, D. (2014). Arabidopsis WRKY57 functions as a node of convergence for jasmonic acid- and auxin-mediated signaling in jasmonic acid-induced leaf senescence. The plant cell, 26 , 230-245.

Jibran, R., A. Hunter, D., \& P. Dijkwel, P. (2013). Hormonal regulation of leaf senescence through integration of developmental and stress signals. Plant Molecular Biology, 82, 547-561.

Keech, O., Pesquet, E., Ahad, A., Askne, A., Nordvall, D., Vodnala, S. M., Tuominen, H., Hurry, V., Dizengremel, P., \& Gardestrom, P. (2007). The different fates of mitochondria and chloroplasts during dark-induced senescence in Arabidopsis leaves. Plant Cell \& Environment, 30 , 1523-1534.

Keech, O., Pesquet, E., Gutierrez, L., Ahad, A., Bellini, C., Smith, S. M., \& Gardestrom, P. (2010). Leaf senescence is accompanied by an early disruption of the microtubule network in Arabidopsis. Plant Physiology, 154, 1710-1720.

Kim, J., Kim, J. H., Lyu, J. I., Woo, H. R., \& Lim, P. O. (2017). New insights into the regulation of leaf senescence in Arabidopsis. Journal of Experimental Botany,69 , 787-799.

Kim, J. I., Murphy, A. S., Baek, D., Lee, S. W., Yun, D. J., Bressan, R. A., \& Narasimhan, M. L. (2011). YUCCA6 over-expression demonstrates auxin function in delaying leaf senescence in Arabidopsis thaliana. Journal of Experimental Botany, 62, 3981-3992.

Lam, E. (2004). Controlled cell death, plant survival and development. Nature Reviews: Molecular Cell Biology, $\mathbf{5}, 305-315$.

Lemoine, R., La Camera, S., Atanassova, R., Dedaldechamp, F., Allario, T., Pourtau, N., Bonnemain, J.-L., Laloi, M., Coutos-Thevenot, P., Maurousset, L., Faucher, M., Girousse, C., Lemonnier, P., Parrilla, J., \& Durand, M. (2013). Source-to-sink transport of sugar and regulation by environmental factors. Frontiers in plant science, 4,272 . 
Leopold, A. C. (1961). Senescence in Plant Development: The death of plants or plant parts may be of positive ecological or physiological value. Science, 134, 1727-1732.

Li, Z., Zhao, Q., \& Cheng, F. (2020). Sugar Starvation Enhances Leaf Senescence and Genes Involved in Sugar Signaling Pathways Regulate Early Leaf Senescence in Mutant Rice.Rice Science, 27 , 201-214.

Li, Z., Zhao, Y., Liu, X., Peng, J., Guo, H., \& Luo, J. (2014). LSD 2.0: an update of the leaf senescence database. Nucleic Acids Research, 42 , D1200-D1205.

Liang, C., Wang, Y., Zhu, Y., Tang, J., Hu, B., Liu, L., Ou, S., Wu, H., Sun, X., Chu, J., \& Chu, C. (2014). OsNAP connects abscisic acid and leaf senescence by fine-tuning abscisic acid biosynthesis and directly targeting senescence-associated genes in rice. Proceedings of the National Academy of Sciences, USA, 111, 10013-10018.

Lim, J., Park, J. H., Jung, S., Hwang, D., Nam, H. G., \& Hong, S. (2018). Antagonistic Roles of PhyA and PhyB in Far-Red Light-Dependent Leaf Senescence in Arabidopsis thaliana. Plant \& Cell Physiology, 59, 1753-1764.

Lim, P. O., Kim, H. J., \& Nam, H. G. (2007). Leaf senescence. Annual Review of Plant Biology,58 , 115-136.

Lim, P. O., Lee, I. C., Kim, J., Kim, H. J., Ryu, J. S., Woo, H. R., \& Nam, H. G. (2010). Auxin response factor 2 (ARF2) plays a major role in regulating auxin-mediated leaf longevity. Journal of Experimental Botany, 61, 1419-1430.

Lim, P. O., Woo, H. R., \& Nam, H. G. (2003). Molecular genetics of leaf senescence in Arabidopsis. Trends in Plant Science, 8 , 272-278.

Lin, J. F., \& Wu, S. H. (2004). Molecular events in senescing Arabidopsis leaves. Plant Journal,39, 612-628.

Liu, T., Gu, L., Dong, S., Zhang, J., Liu, P., \& Zhao, B. (2015). Optimum leaf removal increases canopy apparent photosynthesis, 13C-photosynthate distribution and grain yield of maize crops grown at high density. Field Crops Research, $\mathbf{1 7 0}, 32-39$.

Ma, L., Tian, T., Lin, R., Deng, X. W., Wang, H., \& Li, G. (2016). Arabidopsis FHY3 and FAR1 Regulate Light-Induced myo-Inositol Biosynthesis and Oxidative Stress Responses by Transcriptional Activation of MIPS1. Molecular plant,9, 541-557.

Masclaux-Daubresse, C., Reisdorf-Cren, M., \& Orsel, M. (2008). Leaf nitrogen remobilisation for plant development and grain filling. Plant Biology, 1023-36.

Matyssek, R., Schnyder, H., Elstner, E. F., Munch, J. C., Pretzsch, H., \& Sandermann, H. (2002). Growth and Parasite Defence in Plants; the Balance between Resource Sequestration and Retention: In Lieu of a Guest Editorial. Plant Biology,4, 133-136.

Meng, Y., Chen, F., Shuai, H., Luo, X., Ding, J., Tang, S., Xu, S., Liu, J., Liu, W., \& Du, J. (2016). Karrikins delay soybean seed germination by mediating abscisic acid and gibberellin biogenesis under shaded conditions. Scientific reports, 6 , 1-12.

Murad, M., Razi, K., Benjamin, L., Lee, J., Kim, T.-H., \& Muneer, S. (2021). Ethylene regulates sulfur acquisition by regulating the expression of sulfate transporter genes in oilseed rape. Physiologia Plantarum, $171,533-545$.

Mutlu, S., Atici, O., Nalbantoğlu, B., \& Mete, E. (2016). Exogenous salicylic acid alleviates cold damage by regulating antioxidative system in two barley ( Hordeum vulgare L.) cultivars. Frontiers in Life Science , 1-10.

Paparelli, E., Parlanti, S., Gonzali, S., Novi, G., Mariotti, L., Ceccarelli, N., van Dongen, J. T., Kölling, K., Zeeman, S. C., \& Perata, P. (2013). Nighttime sugar starvation orchestrates gibberellin biosynthesis and plant growth in Arabidopsis. The plant cell, 25 , 3760-3769. 
Peuke, A. D., Rokitta, M., Zimmermann, U., Schreiber, L., \& Haase, A. (2001). Simultaneous measurement of water flow velocity and solute transport in xylem and phloem of adult plants of Ricinus communis over a daily time course by nuclear magnetic resonance spectrometry. Plant Cell $\&$ Environment, 24, 491-503.

Pons, T. L., \& de Jong, V. A. N. B. Y. E. (2004). Species-specific variation in the importance of the spectral quality gradient in canopies as a signal for photosynthetic resource partitioning. Annals of Botany, $\mathbf{9 4}$, 725-732.

Quirino, B. F., Noh, Y. S., Himelblau, E., \& Amasino, R. M. (2000). Molecular aspects of leaf senescence. Trends In Plant Science, 5 , 278-282.

Riesmeier, J. W., Willmitzer, L., \& Frommer, W. B. (1992). Isolation and characterization of a sucrose carrier cDNA from spinach by functional expression in yeast. EMBO Journal, 11 , 4705-4713.

Rousseaux, M. C., Ballar, C. L., Jordan, E. T., \& Vierstra, R. D. (1997). Directed overexpression of PHYA locally suppresses stem elongation and leaf senescence responses to far-red radiation. Plant Cell \& Environment, $20,1551-1558$.

Rousseaux, M. C., Hall, A. J., \& Sánchez, R. A. (1996). Far-red enrichment and photosynthetically active radiation level influence leaf senescence in field-grown sunflower.Physiologia Plantarum, 96 , 217-224.

Sakuraba, Y., Jeong, J., Kang, M., Kim, J. H., Paek, N., \& Choi, G. (2014). Phytochrome-interacting transcription factors PIF4 and PIF5 induce leaf senescence in Arabidopsis. Nature Communications, 5 , 4636.

Sauer, N. (2007). Molecular physiology of higher plant sucrose transporters. FEBS Letters,581 , 2309-2317.

Schippers, J. H., Jing, H.-C., Hille, J., \& Dijkwel, P. P. (2007). Developmental and hormonal control of leaf senescence. Senescence processes in plants, $26,145-170$.

Schippers, J. H., Schmidt, R., Wagstaff, C., \& Jing, H. C. (2015). Living to Die and Dying to Live: The Survival Strategy behind Leaf Senescence. Plant Physiology,169, 914-930.

Shoji, K., Addicott, F. T., \& Swets, W. A. (1951). AUXIN IN RELATION TO LEAF BLADE ABSCISSION. Plant Physiology, 26 , 189-191.

Smart, C. M. (1994). Gene expression during leaf senescence. New Phytologist, 126 , 419-448.

Spundova, M., Sloukova, K., Schaffer, M., \& Naus, J. (2005). Plant shading increases lipid peroxidation and intensifies senescence-induced changes in photosynthesis and activities of ascorbate peroxidase and glutathione reductase in wheat.Photosynthetica, $\mathbf{4 3}, 403-409$.

Stitt, M., \& Zeeman, S. C. (2012). Starch turnover: pathways, regulation and role in growth. Current Opinion in Plant Biology, 15, 282-292.

Streb, S., \& Zeeman, S. C. (2012). Starch Metabolism in Arabidopsis. The Arabidopsis Book,2012 .

Sun, J., Qi, L., Li, Y., Chu, J., \& Li, C. (2012). PIF4-Mediated Activation of YUCCA8 Expression Integrates Temperature into the Auxin Pathway in Regulating Arabidopsis Hypocotyl Growth. PLoS Genetics, 8 , e1002594.

Sun, W., Hui Xu, X., Lu, X., Xie, L., Bai, B., Zheng, C., Sun, H., He, Y., \& Xie, X. Z. (2017). The Rice Phytochrome Genes, PHYA and PHYB, Have Synergistic Effects on Anther Development and Pollen Viability. Scientific reports, $7,6439$.

Sun, X., Lu, J., Yang, M., Huang, S. R., Du, J., Wang, X., \& Yang, W. (2019). Light-induced systemic signalling down-regulates photosynthetic performance of soybean leaves with different directional effects. Plant Biology, 21 , 891-898. 
Tadahiko, M., Howard, T., Gay, A. P., Amane, M., \& Jun, H. (1993). Leaf Development in Lolium temulentum: Photosynthesis and Photosynthetic Proteins in Leaves Senescing under Different Irradiances. Plant \& Cell Physiology, 391-399.

Tang, Z. Q., Shang, J., Zhang, L., Du, J. B., Yang, H., Zeng, S. H., Li, P. L., Bawa, G., Yu, L., \& Hou, X. X. (2019). Characterization of synergy between Cucumber mosaic virus and Alternaria alternata in Nicotiana tabacum. Physiological Molecular Plant Pathology, 108 , 101404.

Thalmann, M., Pazmino, D., Seung, D., Horrer, D., Nigro, A., Meier, T., Kolling, K., Pfeifhofer, H. W., Zeeman, S. C., \& Santelia, D. (2016). Regulation of Leaf Starch Degradation by Abscisic Acid Is Important for Osmotic Stress Tolerance in Plants. The plant cell, 28 , 1860-1878.

Tiwari, S. B., Hagen, G., \& Guilfoyle, T. (2003). The roles of auxin response factor domains in auxinresponsive transcription. The plant cell, $15,533-543$.

Trejo-Arellano, M. S., Mehdi, S., de Jonge, J., Dvorak Tomastikova, E., Kohler, C., \& Hennig, L. (2020). Dark-Induced Senescence Causes Localized Changes in DNA Methylation.Plant Physiology, 182 , 949-961.

Uzelac, B., Janošević, D., Simonović, A., Motyka, V., Dobrev, P. I., \& Budimir, S. (2016). Characterization of natural leaf senescence in tobacco (Nicotiana tabacum) plants grown in vitro. Protoplasma, 253 , 259-275.

van Doorn, W. G. (2008). Is the onset of senescence in leaf cells of intact plants due to low or high sugar levels? Journal Of Experimental Botany, 59, 1963-1972.

Velerskov, B. (2006). Irradiance-dependent senescence of isolated leaves. Physiologia Plantarum, 71 , 316320 .

Wang, H., \& Wang, H. (2015). Multifaceted roles of FHY3 and FAR1 in light signaling and beyond. Trends in Plant Science, 20 , 453-461.

Wang, L., Fan, L., Loescher, W., Duan, W., Liu, G., Cheng, J., Luo, H., \& Li, S. (2010). Salicylic acid alleviates decreases in photosynthesis under heat stress and accelerates recovery in grapevine leaves. $B M C$ Plant Biology, 10,34 .

Wang, L., Wu, L. M., Greaves, I. K., Zhu, A., Dennis, E. S., \& Peacock, W. J. (2017a). PIF4-controlled auxin pathway contributes to hybrid vigor in Arabidopsis thaliana.Proceedings of the National Academy of Sciences, USA,114, E3555-E3562.

Wang, N., Zhang, W., Qin, M., Li, S., Qiao, M., Liu, Z., \& Xiang, F. (2017b). Drought Tolerance Conferred in Soybean (Glycine max. L) by GmMYB84, a Novel R2R3-MYB Transcription Factor. Plant 83 Cell Physiology, 58 , 1764-1776.

Wu, X., Ding, D., Shi, C., Xue, Y., Zhang, Z., Tang, G., \& Tang, J. (2016). microRNA-dependent gene regulatory networks in maize leaf senescence. BMC plant biology,16 , 73-73.

Xu, C., Tao, H., Wang, P., \& Wang, Z. (2016). Slight shading after anthesis increases photosynthetic productivity and grain yield of winter wheat (Triticum aestivum L.) due to the delaying of leaf senescence. Journal of Integrative Agriculture, 15 , 63-75.

Zaidi, N., Tahir, M. W., Vinayaka, P. P., Lucklum, F., Vellekoop, M., \& Lang, W. (2016). Detection of Ethylene Using Gas Chromatographic System. Procedia Engineering,168 , 380-383.

Zhang, Z. W., Feng, L. Y., Cheng, J., Tang, H., Xu, F., Zhu, F., Zhao, Z. Y., Yuan, M., Chen, Y. E., Wang, J. H., Yuan, S., \& Lin, H. H. (2013). The roles of two transcription factors, ABI4 and CBFA, in ABA and plastid signalling and stress responses. Plant Molecular Biology, 83 , 445-458.

Zhang, Z. W., Wu, Z. L., Feng, L. Y., Dong, L. H., Song, A. J., Yuan, M., Chen, Y. E., Zeng, J., Chen, G. D., \& Yuan, S. (2016). Mg-Protoporphyrin IX Signals Enhance Plant's Tolerance to Cold Stress. Frontiers in plant science, 7,1545 . 
Zhao, Y., Chan, Z., Gao, J., Xing, L., Cao, M., Yu, C., Hu, Y., You, J., Shi, H., Zhu, Y., Gong, Y., Mu, Z., Wang, H., Deng, X., Wang, P., Bressan, R. A., \& Zhu, J. K. (2016). ABA receptor PYL9 promotes drought resistance and leaf senescence.Proceedings of the National Academy of Sciences, USA,113 , 1949-1954.

\section{Hosted file}

Figure.docx available at https://authorea.com/users/455774/articles/553054-heterogeneouslight-delayed-leaf-senescence-and-ensure-yield-in-maize

\section{Hosted file}

Table.docx available at https://authorea.com/users/455774/articles/553054-heterogeneouslight-delayed-leaf-senescence-and-ensure-yield-in-maize 